\title{
¿Elena G. de White utilizó terminología masónica?
}

\author{
Eric E. Richter \\ ericrichter17@gmail.com \\ Facultad de Teología \\ Universidad Adventista del Plata
}

Recibido: 20 junio de 2017

Aceptado: 15 de julio de 2017

\section{Introducción}

Elena G. de White fue una prolífica escritora, con alrededor de 100.000 páginas escritas y más de 60 libros. Como es de esperar en un cuerpo literario tan extenso, en sus escritos se encuentran algunas expresiones y frases que son difíciles de explicar y que los críticos han utilizado para hacer toda clase de acusaciones. Una de estas expresiones es "el ojo que todo lo ve" (all-seeing eye), que fue usada al menos en 72 ocasiones diferentes por Elena G. de White. ${ }^{122}$ Dado que en la actualidad esta frase tiene connotaciones masónicas, sus críticos han afirmado que Elena G. de White perteneció a alguna sociedad secreta masónica. ${ }^{123}$ En este artículo analizaremos esta acusación y veremos realmente qué relación hay

${ }^{122}$ Búsqueda realizada en https://egwwritings.org/ (consultado el 15 de junio de 2017).

${ }^{123}$ Ver, por ejemplo, Mario Olcese Sanguineti, "Elena G. de White definió a su deidad de la masonería: "El ojo que todo lo ve"”, disponible en https://apologista.wordpress.com/2012/05/27/elena-g-de-white-definio-sudeidad-de-la-masoneria-el-ojo-que-todo-lo-ve/ (consultado el 22 de mayo de 2017). 
entre la frase "el ojo que todo lo ve" y la masonería. También buscaremos una explicación del porqué Elena G. de White utilizó esta expresión en sus escritos.

\section{El ojo que todo lo ve en la antigüedad}

Muchas culturas y civilizaciones antiguas utilizaron el símbolo del ojo como parte de su arte, religión e iconografía. En Egipto el ojo era relacionado a Ra, Osiris y Horus. ${ }^{124}$ En ocasiones el ojo era representado rodeado de rayos luminosos, ya que también se lo relacionaba con el sol.

Dado que el ojo es el órgano más relacionado con la percepción de la realidad, era utilizado como un símbolo de inteligencia y sabiduría, aunque también poseía una connotación sobrenatural o extrasensorial. Su uso relacionado con los dioses hacía hincapié en su omnipresencia y omnisciencia. ${ }^{125}$

Aunque la figura del ojo se utilizó en diversas culturas antiguas como un símbolo divino, también fue empleado en el Antiguo Testamento. ${ }^{126}$ Se han encontrado amuletos judíos con representaciones de un ojo que probablemente simbolice la protección divina. ${ }^{127}$

${ }^{124}$ Juan-Eduardo Cirlot, Diccionario de Símbolos (Barcelona: Editorial Labor, 1992), 339-340

${ }^{125}$ Ibíd.

${ }^{126}$ Erik Thunø, The Apse Mosaic in Early Medieval Rome (Cambridge: Cambridge University Press, 2015), 139-140. Es comúnmente aceptado que, "de acuerdo a creencias antiguas, a las que tanto paganos como judíos estaban familiarizados, el ojo abierto y vigilante era el símbolo de la Deidad inmortal y siempre alerta". Eduard Syndicus, Early Christian Art (New York: Hawthorn, 1962), 110.

${ }^{127}$ Alen H. Barber, Celestial Symbols: Symbolism in Doctrine, Religious Tradition and Temple Architecture (Cedar Fort, 2006), 25 
En ocasiones, la Biblia hace referencia al "ojo" de Dios como un símbolo o figura de la presencia y omnisciencia divina. Por ejemplo, Salomón escribió: "Los ojos de Jehová están en todo lugar, Mirando a los malos y a los buenos" (Pr 15:3; cf. 1 P 3:12). ${ }^{128}$ El Salmista cantaba: "He aquí el ojo (עִין) de Jehová sobre los que le temen, Sobre los que esperan en su misericordia" (Sal 33:18). Es interesante que en este versículo el sustantivo hebreo "ojo" está en singular (cf. Dt 32:10; Sal 17:8).

\section{El ojo que todo lo ve en el cristianismo}

Con la aparición del cristianismo el símbolo del ojo fue "un símbolo temprano" para representar a "Dios el Padre antes de que sea representado en forma humana". ${ }^{129}$ Aunque algunos piensan que es una adaptación de un motivo artístico pagano, George Ferguson le adjudica un origen bíblico, alegando que "debido a las muchas referencias escriturales al ojo de Dios, el ojo ha llegado a simbolizar al omnisapiente y omnipresente Dios". ${ }^{130}$

A la figura del ojo pronto se agregó un triángulo para simbolizar la Trinidad. ${ }^{131}$ Este símbolo se volvió particularmente común durante el Renacimiento, llegando a ser usualmente conocido como "el ojo de la Providencia" o "el ojo de Dios". ${ }^{132}$

${ }^{128} \mathrm{~A}$ menos que se indique algo diferente, todas las citas bíblicas han sido tomadas de la Reina Valera de 1960.

${ }^{129}$ James Hall, Dictionary of Subjects and Symbols in Art (New York: Haper \& Row, 1974), 118.

${ }^{130}$ George Ferguson, Signs \& Symbols in Christian Art (New York: Oxford University Press, 1967), 26. A menos que se indique algo diferente, todas las citas traducidas del inglés son del autor.

${ }^{131}$ James Hall, Illustrated Dictionary of Symbols in Eastern and Western Art (Boulder, CO: Westview Press, 1996), 121, 207.

${ }^{132}$ Micah Lee Issitt y Carlyn Main, Hidden Religion: The Greatest Mysteries and Symbols of the World's Religious Beliefs (Santa Bárbara, CA: ABCCLIO, 2014), 48-49. 


\section{Introducción del símbolo a la masonería}

El hecho de que el "ojo que todo lo ve" se usó por siglos en el arte cristiano, mucho antes de la aparición de las logias masónicas, nos indica que, obviamente, la masonería lo tomó del cristianismo. Al estudiar la historia del símbolo, podemos concluir que el origen del símbolo es cristiano y que recién a fines del siglo XVIII y comienzos del XIX el símbolo fue introducido a la masonería. S. Brent Morris, especialista en historia masónica, confirma esto diciendo:

El ojo que todo lo ve parece ser más bien una adición reciente al simbolismo masónico. No es encontrado en ninguna de las Constituciones Góticas escritas desde 1390 hasta 1730. [...] Su uso como un elemento decorativo parece haber sido una representación artística de la omnisciencia de Dios más que algún símbolo masónico generalmente aceptado. ${ }^{133}$

Existen otras evidencias históricas que demuestran esto. Por ejemplo, el "ojo que todo lo ve" aparece en numerosas obras artísticas siglos antes de que aparecieran las primeras logias masónicas. Por ejemplo, el pintor renacentista Pontormo (1494-1557), en su pintura llamada "Cena en Emaús" (1525), retrató el "ojo que todo lo ve" en la parte superior, a pesar de que esta obra fue creada casi doscientos años antes de la aparición de la primera logia masónica especulativa conocida. ${ }^{134}$

${ }^{133}$ S. Brent Morris, "The Eye in the Pyramid", Short Talk Bulletin 73/9 (1995): 3.

${ }^{134}$ Se considera que la Gran Logia Unida de Inglaterra es la primera logia de masonería especulativa (mística) que se formó en la historia. Las actas 


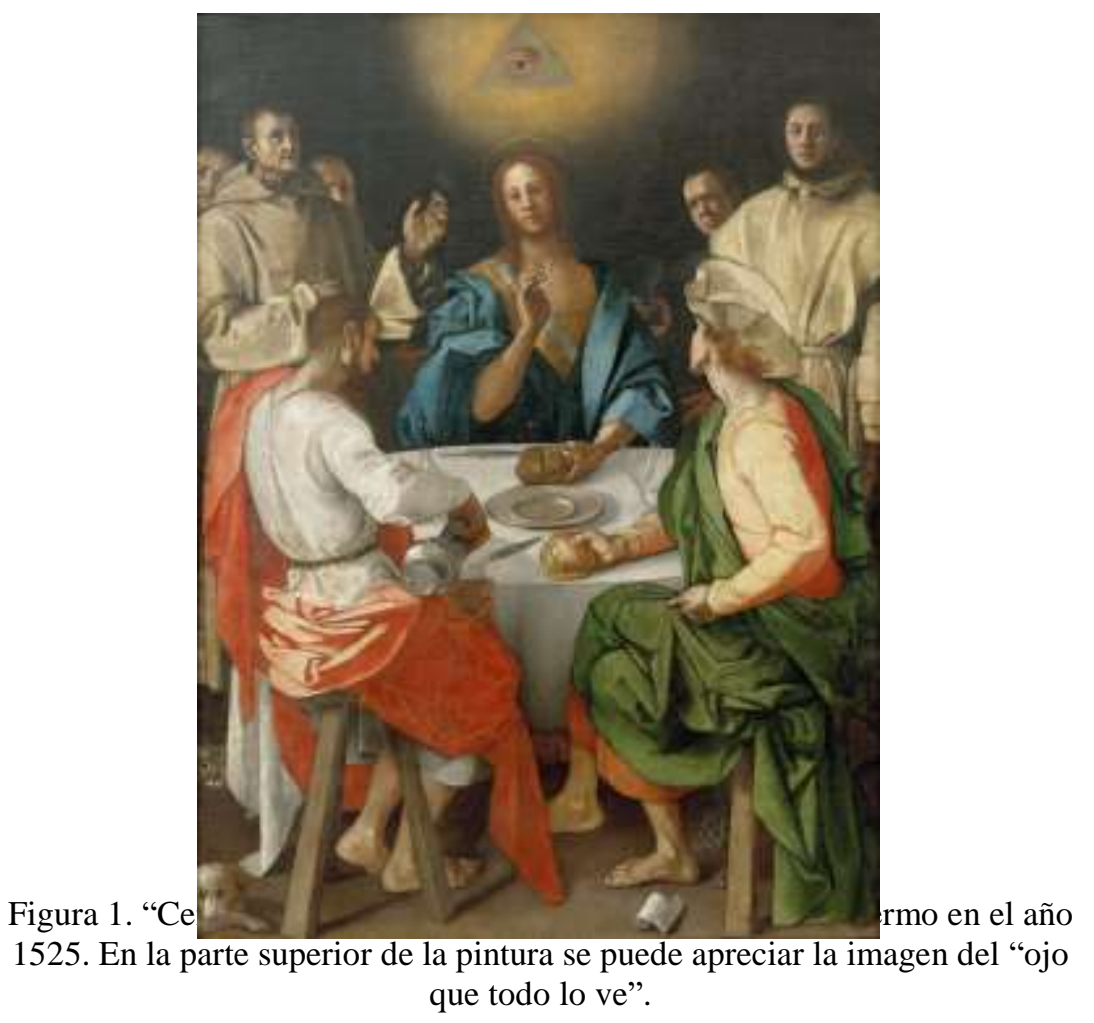

de la logia comienzan en 1717, aunque es probable que haya grupos masónicos ya a mediados del siglo XVII. Ver David Stevenson, The Origins of Freemasonry: Scotland's Century, 1590-1710 (Cambridge: Cambridge University Press, 1990). 
Esta pintura es una clara evidencia de que el "ojo que todo lo ve" era considerado como un símbolo artístico de la omnisciencia de Dios siglos antes de que apareciera la francmasonería.

El motivo por el cual este símbolo fue incorporado a la masonería no puede ser precisado con exactitud, pero el hecho de que la mayoría de los gremios de albañiles estuvieran dedicados a la Trinidad puede haber sido un factor importante. ${ }^{135}$

El primer registro masónico en el cual se encuentra la expresión el "ojo que todo lo ve" es un libro titulado Freemasons Monitor, publicado por Thomas Smith Webb en $1797 .{ }^{136}$ Pero recién en la segunda mitad del siglo XIX se convirtió gradualmente en un símbolo masónico común. ${ }^{137}$

\section{El "ojo que todo lo ve" en la literatura cristiana del siglo XIX}

La expresión "el ojo que todo lo ve" continuó siendo usada popularmente en el cristianismo para referirse a la omnisciencia y omnipresencia de Dios incluso después del Renacimiento. Los autores cristianos del siglo XIX utilizaron esta expresión abundantemente. No hay evidencia de que ellos consideraran que tenía alguna clase de connotación masónica.

Un ejemplo que puede ilustrar muy bien el profuso uso de la expresión puede encontrarse en Charles Spurgeon (18341892), el famoso predicador bautista. Entre sus sermones escritos

${ }^{135}$ Peter y Linda Murray, The Oxford Companion to Christian Art and Architecture (New York. Oxford University Press, 1996), 177.

${ }^{136}$ Morris, "The Eye in the Pyramid", 3.

${ }^{137}$ Ibíd., 4. 
la frase aparece más de 60 veces. ${ }^{138}$ Pero él no es el único en utilizar la frase "el ojo que todo lo ve", ya que decenas de escritores cristianos la utilizaron en el siglo XIX. Entre ellos se cuentan el reverendo presbiteriano Alexander Topp (ca. 1878), ${ }^{139}$ el teólogo reformista John William McGarvey (1829-1911), ${ }^{140}$ el arzobispo anglicano Richard Chenevix Trench (1807-1886), ${ }^{141}$ el clérigo

${ }^{138}$ Búsqueda realizada en Classical Christian Ethereal Library, disponible en http://ccel.org (consultado: 15 de junio, 2017).

139،"Seguramente entonces, la verdad a la cual me refiero es una de elevada importancia: la Omnisciencia de Dios, la verdad de que su Ojo que todo lo ve está siempre sobre nosotros". Alexander Topp, The All-Seeing Eye of God: a New Year's Addres to the young connected with Knox Church [in] Toronto, (Toronto: Globe Printing Company, 1878), 4.

140،"Pero Pablo fue a menudo guiado simplemente por las indicaciones de la Providencia, y así puede suceder con ustedes. Si estamos atentos a esas indicaciones, estaremos bajo la orientación del mismo Ojo que todo lo ve que decidió los pasos de Pablo". John William McGarvey, Commentary on the Acts of the Apostles (Cincinnati: Wrightson, 1863), 200.

141 “En esta última forma, las palabras son generalmente entendidas como el Señor declarando lo que, en su ojo que todo lo ve, fue la verdadera naturaleza de $\mu \varepsilon \gamma \alpha \lambda$ o’ $\rho \eta \mu o \sigma v ́ v \alpha 1$, las "grandes palabras infladas de vanidad" que estos gnósticos descargaron, prometiendo libertad a otros, siendo que ellos mismos eran esclavos de la corrupción". Richard Chenevix Trench, Commentary on the Epistles to the Seven Churches in Asia (New York, Charles Scribner, 1863), 194. 
bautista Alexander McLaren (1826-1910), ${ }^{142}$ el ministro persbiteriano John Dick (1764-1833), ${ }^{143}$ el cardenal católico Henry Edward Manning (1808-1892), ${ }^{144}$ la escritora cuáquera Hanna

${ }^{142}$ “ $\mathrm{Ni}$ en la sabiduría que no conoce crecimiento, ni en el conocimiento que no tiene frontera de ignorancia a su alrededor, ni en incansable poder de su brazo, ni en la inacabable energía de su ser, ni en la vigilancia ininterrumpida de su ojo que todo lo ve, ni en la presencia de donde sea de sus criaturas estén, ni en nada de esto yace la gloria de Dios, sino en su amor." Alexander McLaren, Expositions of the Holy Scriptures: Second Corinthians, Galatians, and Philippians, Colossians, Thessalonians, and First Timothy (New York: George H. Doran, 1910), 312-313.

143“"El mismo no santificado amor a la reputación, la misma base de hipocresía, la misma indiferencia hacia el ojo que todo lo ve de los cielos, influye a ambos [Ananías y Safira]. Ellos fueron odiosos en sus vidas y en su muerte no estuvieron separados. Ellos perecieron mediante la misma destrucción y su fin ministra una solemne advertencia a otros, para que puedan escuchar y temer y no actuar más impíamente". John Dick, Lectures on the Acts of the Apostles, 2da ed. (New York: Robert Carter \& Brothers, 1857), 81.

144،"El mundanal, trivial, iluminado, el impuro, falso y sensual; aun los blasfemos, burladores, infieles, todos están atados a una cadena de consciencia, la cual, es como lo oculto, pero el Ojo que todo lo ve los sigue a todas partes. Los aguijonea con temor y, cuando pecan, vuelve sus corazones dentro de ellos en piedra". Henry Edward Manning, Sermons, vol. 3 (Londres, James Burns, 1847). 24. 
Whitell Smith (1832-1911), ${ }^{145}$ el misionero de la Iglesia Reformada Holandesa Andrew Murray (1828-1917), ${ }^{146}$ el autor anglicano John Newton (1725-1807), ${ }^{147}$ el poeta y ministro unitario Samuel Longfellow (1819-1892), ${ }^{148}$ y el poeta anglicano Francis Turner Palgrave (1824-1897). ${ }^{149}$

Si utilizamos la lógica de los críticos de Elena G. de White, entonces deberíamos concluir que todos estos autores pertenecían a alguna logia masónica. Sin embargo, la explicación más lógica es asumir que todos ellos usaban una expresión que era común en su tiempo para referirse a la omnisapiencia y omnipresencia de Dios. El hecho de que estos autores pertenecieran a diferentes denominaciones y ramas del cristianismo reafirma la idea de que esta frase no

145“¿Cómo hará su dueño para recibir la inteligencia? ¿Invocará mediante una ansiosa acción de gracias y abrirá cada puerta para la entrada de su glorioso Invitado? ¿O disminuido y vacilante, temeroso de su presencia, buscará convertir alguna esquina privada en un refugio de su ojo que todo lo ve?". Hanna Whitell Smith, Christian's Secret of a Happy Life (New York: Fleming H. Revell, 1916), 226.

146،"Esta es la bendición de esperar en Dios, que Él toma nuestros ojos y pensamientos de nosotros mismos, incluso nuestras necesidades y deseos, y los ocupa con nuestro Dios. Nosotros lo adoramos en su gloria y amor, con su ojo que todo lo ve observándonos a nosotros, sabiendo que Él suplirá todas nuestras necesidades". Andrew Murray, Waiting on God (1889), 54.

${ }^{147}$ En su famoso himno Amazing Grace escribió "Ahora de la voz de su Creador él (Adán) huye, La cual fue antes su alegría, Y piensa en esconderse entre los árboles, De un ojo que todo lo ve". Ver, Olney Hymns (1779), 2, Himno 1.

148“Sé tú mi guía, y déjame vivir, Como bajo tu Ojo que todo lo ve, Provee mis deseos, mis pecados perdona, Y hazme feliz cuando muera". Books of Hymns for public and private devotion (Boston: James R. Osgood, 1871), 366.

149“‘Quédate quieta, triste alma! No eleves un grito apasionado, Sino abre el desierto de tu ser descubierto, Al escrudiño completo del Ojo que todo lo ve". Treasury of Sacred Song (Oxford: Clarendon Press, 1890), 280. 
tenía connotaciones masónicas, sino que continuaba siendo una expresión cristiana común.

La conclusión más lógica es que el empleo de la expresión por parte de Elena G. de White se enmarca dentro de su uso común en la literatura cristiana del siglo XIX. Es decir, para ella, esta frase era una referencia a la omnisapiencia y omnipresencia de Dios que no tenía vínculos masónicos en absoluto.

Esta interpretación es consistente con la actitud que Elena G. de White tenía hacia la masonería en general. Es bien sabido que ella era "una opositora declarada de la masonería", 150 que incluso creía en "la imposibilidad de que un hombre sea masón y un cristiano sincero [a la vez]". ${ }^{151}$ En 1893, Elena G. de White escribió el folleto Should Christians Be Members of Secret Societies? (¿Deberían los cristianos ser miembros de sociedades secretas?), ${ }^{152}$ en el cual condenó con dureza a aquellos cristianos que consideraban aceptable unirse a logias masónicas y otras sociedades. Ella amonestó a los adventistas a no asociarse "con los francmasones ni con ninguna otra organización secreta". ${ }^{153}$ Es ilógico suponer que una opositora tan férrea de la masonería llegaría a utilizar su terminología.

\section{Conclusión}

La evidencia histórica nos muestra que la expresión "ojo que todo lo ve" no tiene un origen masónico, sino cristiano. Durante siglos fue un motivo artístico común para describir la omnisciencia y

${ }^{150}$ William Fagal, 101 Preguntas acerca de Elena G. de White y sus Escritos (Buenos Aires: Asociación Casa Editora Sudamericana, 2015), 32.

${ }^{151}$ Arthur L. White, Ellen White: Woman of Vision (Hagerstown, MD: Review and Herald, 2000), 287.

${ }^{152}$ Republicado en Mensajes Selectos, 3 vols. (Mountain View, CA: Pacific Press, 1966, 1967, 2000), 2:139-160. Ver también, El Evangelismo (Miami, FL: Asociación Publicadora Interamericana, 1994), 448-452.

${ }^{153}$ Ibíd., 451. 
omnipresencia de Dios. Las primeras logias masónicas no utilizaron este símbolo, y no fue sino hasta fines del siglo XVIII y comienzos del XIX que comenzó a ingresar gradualmente a la masonería. No obstante, durante el siglo XIX la expresión "el ojo que todo lo ve" continuaba siendo una frase cristiana común, relacionada a la omnisapiencia divina. Fue con este significado que numerosos autores cristianos, procedentes de diferentes trasfondos denominacionales, la emplearon en sus obras literarias; entre ellos, debemos concluir, se cuenta a Elena G. de White. La férrea oposición que manifestó hacia las logias masónicas y las sociedades secretas hace improbable que ella utilizara terminología que en su tiempo estaba asociada a ellas.

Respondiendo a la pregunta del título, ¿Elena G. de White utilizó terminología masónica? Podemos concluir que no, que no lo hizo. Sencillamente usó una expresión común de su tiempo para describir la omnisciencia de Dios. 


\section{Recensiones bibliográficas}

D

Berit Olam 14/1 (2017): xx-xx / ISSN 2305-5588 